\title{
Empirical Analysis of RMB Exchange Rate Variation Based on Elastic Price Currency Model
}

\author{
Shichao Hu ${ }^{1}$, Qing Mao ${ }^{2}$, Xinxin Jing ${ }^{1, *}$ \\ ${ }^{1}$ School of Finance, Zhongnan University of Economics and Law, Wuhan, 430070, China \\ ${ }^{2}$ Economics and Management School, Wuhan University, Wuhan, 430073, China
}

Keywords: monetarism, RMB exchange rate, excessive currency, vector auto-regression

\begin{abstract}
In the past few years, the rise of Chinese economy in the world is commonly witnessed, so RMB exchange rate has gradually become an economic variable affecting the world economy that cannot be neglected. Under this background, this paper combines with monetarism research framework with mature foreign research, takes the currency model of elastic prices as the starting point, and establishes vector auto-regression model to study the factors influencing RMB exchange rate variation. Because there are rare researches on this aspect domestically, RMB exchange rate is the important economic variable gradually concentrated by domestic and foreign scholars, this paper also equips with significant theoretical and realistic meaning. The main discoveries of this paper include: 1. Excessive currency has the biggest effects on RMB exchange rate. 2. The pushing appreciation function of domestic economic increases (including first order lagging term) on RMB exchange rate. 3 . The increase of current domestic $\mathrm{v}$ and FIR value will all lead to the depreciation trend of RMB exchange rate.
\end{abstract}

On the basis of empirical research conclusion, this paper puts forward political advices: improving the property rights system; optimizing economic increase mode, improving the domestic market efficiency; loosing the management and supervision degree on capital account.

\section{Introduction}

In recent years, the rise of Chinese economy in the world is commonly witnessed, so RMB exchange rate has gradually become the economic variable affecting the world economy that cannot be neglected. With the constant promotion of RMB exchange rate system reform process, RMB has displayed more frequent fluctuation amplitude, and its complex influential factors behind make RMB exchange rate study arouse the extensive attention in the academic world. With the continuously increasing openness degree in China, RMB exchange rate will become the important variable affecting the world economy and receive the attention by scholars in every country [1].

\section{Establishment of Vector Auto-Regression Model}

On the basis of currency model expression, this paper has considered several major exogenous variables and built Vector-Auto-Regression Model, so as to study the relations between RMB exchange rate with excessive currency, economic increase, interest rate level, currency circulation velocity, finance relevance rate and capital account openness degree in the long-term. Firstly, it needs to make the abbreviation treatment on the original theory model: let Loge be $\mathrm{e}_{c}$, namely the logarithm value of RMB exchange rate under the direct bid price method, let LogMs-LogMs* be $\Delta \mathrm{m}_{\mathrm{c}-\mathrm{u}}$, let $\log Y-\log Y^{*}$ be $\Delta \mathrm{y}_{\mathrm{c}-\mathrm{u}}$, let Logi-Logi* be $\Delta \mathrm{i}_{\mathrm{c}-\mathrm{u}}$, Therefore, the basic equation can be abbreviated as the form (1) as below:

$$
e_{c}=\Delta m_{c-u}-\beta \Delta y_{c-u}+\theta \Delta i_{c-u} \ldots
$$




\subsection{Measurement of Exogenous Variables in Vector Auto-Regression Model.}

By analyzing the above paper, it can be known that according to the hypothetical conditions of currency model, the factors influencing exchange rate also include domestic capital account openness degree A-open, finance deepening degree FIR, currency circulation velocity v. Because currency circulation velocity has data to trace, it is not discussed in the following paper, and the quantization problem of two remaining exogenous variables is discussed [2].

\subsubsection{Measurement of capital account openness.}

Because the administrative regulation degree of capital account cannot be directly measured, some scholars even particularly study this administrative regulation extent. Because this problem is not the research emphatic point of this paper, the data to measure the administrative regulation degree of capital account directly stems from Da Lei, Yong Zhao (2008) in China Renmin University, this paper has better measured the administrative regulation degree of capital account. As the research, the expression of capital account's administrative regulation degree is expressed as the following formula in the paper:

$$
\text { open }=\sum_{i=1}^{n} P_{i} / n
$$

\subsubsection{Measurement of financial deepening indexes.}

To consider financial deepening indexes again, actually, numerous scholars have put forward large amounts of indexes to measure finance deepening. After the study by Wang Yi (2002), it is found that financial relevance rate FIR is more proper to Chinese national situation. Therefore, this paper adopts financial relevance rate as the financial deepening index as shown in the following:

$$
\text { FIR= Financial assets/ GDP }
$$

About the issue of how to define financial assets in China, according to the study by Xu Jianjun (2007), this paper discovers that Chinese financial assets deposits can use M2, namely extensive currency balance to express. Therefore, the value of FIR is the ratio of M2 to GDP [3].

\subsection{Quantity Expression of Vector Auto-Regression Model.}

According to the above discussion, three exogenous variables are currently attributed to exchange rate disturbance terms, because they have greater dependency, these three exogenous variables are separated for modeling to avoid the problem of multiple colinearity. Then, the exchange rate decisive model considering Chinese national situation should be:

$$
\begin{aligned}
& X_{k, t}=\left(\begin{array}{cc}
e_{c t} & \Delta m_{(c-u) t} \\
\Delta y_{(c-u) t} & \Delta I_{(c-u) t}
\end{array}\right)=\sum_{i=1}^{4} \sum_{j=1}^{p} a_{i, j}^{k} X_{i, t-j}+\lambda v_{c t}+v_{(t)}(k=1,2,3,4) \\
& X_{k, t}=\left(\begin{array}{cc}
e_{c t} & \Delta m_{(c-u) t} \\
\Delta y_{(c-u) t} & \Delta I_{(c-u) t}
\end{array}\right)=\sum_{i=1}^{4} \sum_{j=1}^{p} a_{i, j}^{k} X_{i, t-j}+\mu O_{c t}+v_{(t)}(k=1,2,3,4) \\
& X_{k, t}=\left(\begin{array}{cc}
e_{c t} & \Delta m_{(c-u) t} \\
\Delta y_{(c-u) t} & \Delta I_{(c-u) t}
\end{array}\right)=\sum_{i=1}^{4} \sum_{j=1}^{p} a_{i, j}^{k} X_{i, t-j}+\alpha \xi_{c t}+v_{(t)}(k=1,2,3,4)
\end{aligned}
$$

\section{Empirical Analysis of RMB Exchange Rate's Influential Factors}

\subsection{Relations between Variables and Model Estimation Results.}

\subsubsection{Main variable descriptive statistics and related coefficients.}

As the following Table 1, it is the descriptive statistical results of main variables in this paper's 
empirical part. With the results of descriptive statistics, the variance and standard deviation of main variables are smaller, matched with the normal distribution of time sequence regression model [4].

Table 1. Descriptive statistics results of main variables

\begin{tabular}{|c|c|c|c|c|c|c|c|}
\hline Index & loge & $\Delta m c-u$ & $\Delta y c-u$ & $\Delta I c-u$ & $\log V$ & $\log O$ & $\log F I R$ \\
\hline Mean & 0.87 & 0.68 & -0.36 & 0.52 & -0.77 & -0.27 & 0.77 \\
\hline Standard error & 0.01 & 0.03 & 0.03 & 0.09 & 0.01 & 0.01 & 0.01 \\
\hline Median & 0.90 & 0.68 & -0.40 & 0.19 & -0.78 & -0.27 & 0.78 \\
\hline $\begin{array}{l}\text { Standard } \\
\text { deviation }\end{array}$ & 0.05 & 0.26 & 0.24 & 0.80 & 0.09 & 0.06 & 0.09 \\
\hline Variance & 0.00 & 0.07 & 0.06 & 0.64 & 0.01 & 0.00 & 0.01 \\
\hline Kurtosis & -1.59 & -1.37 & -1.49 & -1.28 & 0.15 & -1.31 & 0.15 \\
\hline Skewness & -0.42 & 0.00 & 0.19 & 0.47 & 0.52 & -0.12 & -0.52 \\
\hline Region & 0.13 & 0.85 & 0.78 & 2.57 & 0.43 & 0.20 & 0.43 \\
\hline $\begin{array}{l}\text { Minimum } \\
\text { value }\end{array}$ & 0.79 & 0.22 & -0.73 & -0.57 & -0.95 & -0.38 & 0.52 \\
\hline $\begin{array}{l}\text { Maximum } \\
\text { value }\end{array}$ & 0.92 & 1.07 & 0.05 & 1.99 & -0.52 & -0.18 & 0.95 \\
\hline Sum & 74.00 & 57.93 & -30.51 & 44.25 & -65.63 & -22.71 & 65.63 \\
\hline Observations & 85 & 85 & 85 & 85 & 85 & 85 & 85 \\
\hline
\end{tabular}

The following Table 2 reports the related coefficient situation between variables. From the Table, it can be seen that RMB exchange rate level and excessive currency, economic increase difference and interest rate level are significantly related in $1 \%$ level, among which exchange rate is positively related to excessive currency. It means that excessive currency may have the promotion function on RMB depreciation, most of related coefficients explaining variables are lower than 0.5 , and this value illustrates that multiple linear problem doesn’t exist between variables.

Table 2. Correlation coefficients of main variables

\begin{tabular}{|c|c|c|c|c|c|c|c|}
\hline & loge & $\Delta m c-u$ & $\Delta y c-u$ & $\Delta I c-u$ & $\log V$ & $\log O$ & $\log F I R$ \\
\hline Loge & 1.00 & & & & & & \\
\hline$\Delta m c-u$ & $0.93^{* * *}$ & 1.00 & & & & & \\
\hline$\Delta y c-u$ & $-0.95^{* * *}$ & 0.18 & 1.00 & & & & \\
\hline$\Delta I c-u$ & $0.89^{* * *}$ & 0.07 & 0.02 & 1.00 & & & \\
\hline $\log V$ & $0.72^{* *}$ & $-0.16^{*}$ & -0.15 & -0.08 & 1.00 & & \\
\hline $\log O$ & $0.90^{* *}$ & -0.07 & -0.07 & $-0.03^{*}$ & 0.02 & 1.00 & \\
\hline $\log F I R$ & $-0.72^{* * *}$ & 0.06 & 0.15 & 0.18 & -0.01 & -0.02 & 1.00 \\
\hline
\end{tabular}

Note: ${ }^{* * *}, * *$ and * respectively represent significance level of $1 \%, 5 \%$ and $10 \%$

\subsubsection{Serial ADF testing and Johansen testing results.}

Table 3. ADF Test results of main variables

\begin{tabular}{|c|c|c|c|c|}
\hline \multicolumn{5}{|c|}{ ADF Test results of main variables(T-test value, keep two decimals) } \\
\hline $\begin{array}{ll}\text { main variables } & \text { significance level }\end{array}$ & 1\%level & 5\%level & 10\%level & $\begin{array}{l}\text { Unit } \\
\text { root }\end{array}$ \\
\hline Log Average exchange rate: US dollar against RMB & -3.51 & -2.90 & -2.59 & no \\
\hline$\triangle m c-u(\log$ Chinese M2-log American M2) & -3.50 & -2.89 & -2.58 & no \\
\hline Ayc-u(log Chinese GDP-log American GDP) & -3.52 & -2.90 & -2.58 & no \\
\hline $\begin{array}{l}\text { UIc-u(log Chinese interest rate -log American } \\
\text { interest rate) }\end{array}$ & -3.51 & -2.90 & -2.59 & no \\
\hline $\begin{array}{l}\text { log Chinese circulation rate of money income: } \\
\text { GDP/M2 }\end{array}$ & -3.52 & -2.89 & -2.59 & no \\
\hline log control degree of capital account & -3.51 & -2.89 & -2.59 & no \\
\hline log finance relevance rate & -3.52 & -2.90 & -2.59 & no \\
\hline
\end{tabular}


By conducting unit root testing on every sequence, results are obtained in the following Table. From the following Table 3, it can be known that, the main variables in the model are stable sequences in the significance level of $1 \%, 5 \%, 10 \%$, and unit roots don't exist.

In three models, long-term co-integration relations exist. Consequently, it illustrates that variables in this model can explain the long-term fluctuation of RMB exchange rate, and this co-integration relations exist for the long-term.

Table 4. Results of Johansen Cointegration Test

\begin{tabular}{|c|c|c|c|c|c|c|c|}
\hline $\begin{array}{l}\text { VAR } \\
\text { Model }\end{array}$ & Eigenvalue & $\begin{array}{l}\text { Trace } \\
\text { Statistic }\end{array}$ & Comparison & $\begin{array}{l}0.05 \\
\text { Critical } \\
\text { Value }\end{array}$ & $\begin{array}{l}\text { Prob. } \\
* *\end{array}$ & $\begin{array}{l}\text { Hypothesized } \\
\text { No.of CE(s) }\end{array}$ & $\begin{array}{l}\text { Cointegration } \\
\text { relationship }\end{array}$ \\
\hline Model(1) & 0.423 & 83.55 & $>$ & 69.82 & $\begin{array}{c}0.002 \\
7\end{array}$ & None* & Exist \\
\hline Model(2) & 0.401 & 81.49 & $>$ & 69.82 & $\begin{array}{c}0.002 \\
7\end{array}$ & None* & Exist \\
\hline Model(3) & 0.532 & 91.26 & $>$ & 69.82 & $\begin{array}{c}0.000 \\
1\end{array}$ & None* & Exist \\
\hline
\end{tabular}

3.1.3 Model lagged intervals, stability testing, residual independence and auto-correlation testing.

Table 5. Model lagged rank, stationarity test, Residuals independence test and residual autocorrelation test

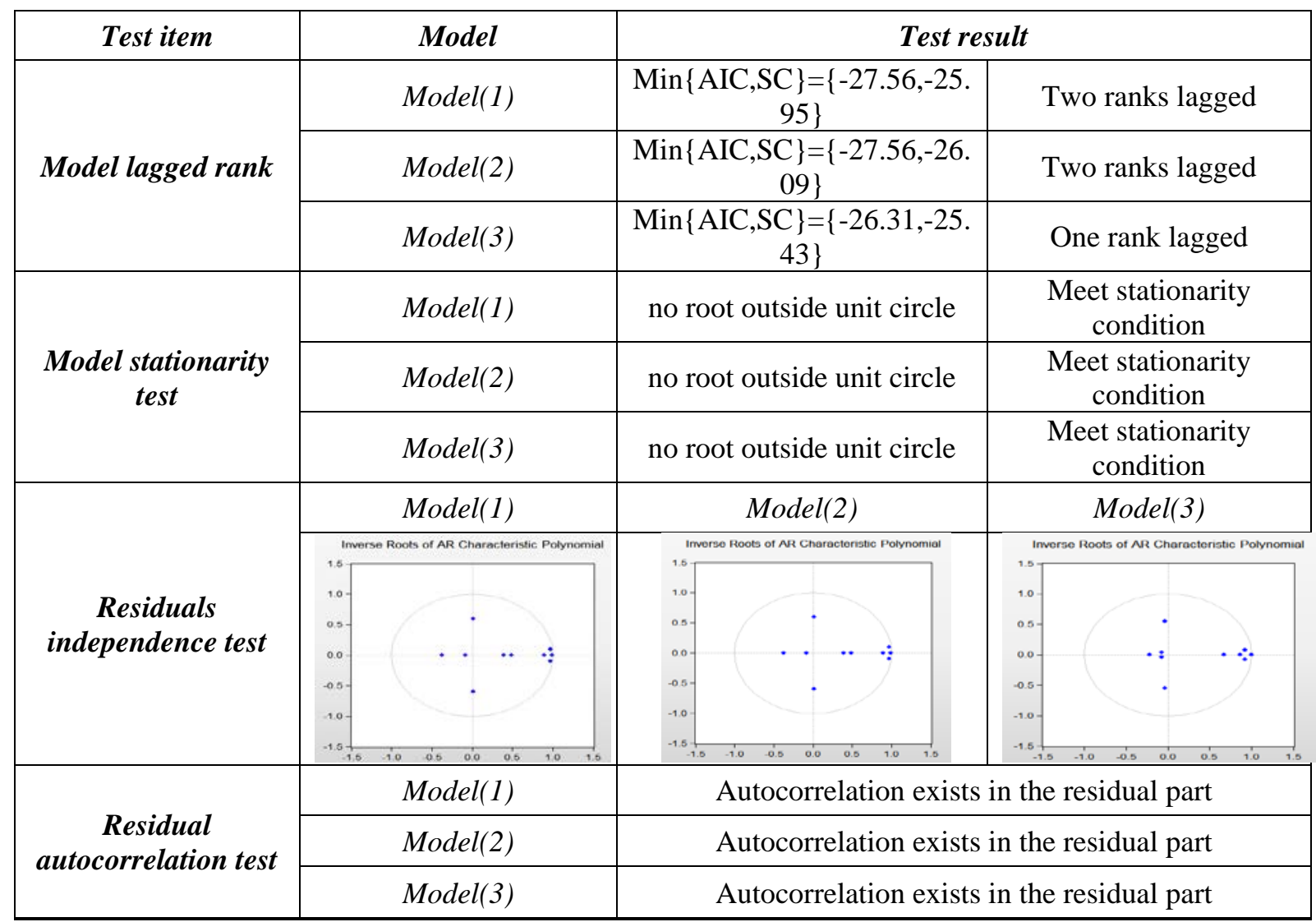

Note: $* * *, * *$ and $*$ respectively represent significance level of $1 \%, 5 \%$ and $10 \%$

After ADF testing and Johansen testing, this paper conducts related testing on the lagged intervals, stability and residual terms of the entire vector auto-regression model, and the testing results are in the following Table 5. From the results in the Table, it can be seen that the lagged intervals of the model is 1-2 order, and three sub-models are sTable, the results of residual independent testing are left within the unit elements, but the residuals in three models exist certain auto-correlation more or less. 


\subsubsection{Estimation results of vector auto-regression model.}

After a series of testing in the above paper, the serial stability and co-integration relations in this model have shown the sTable relations. On this foundation, this paper estimates the model. For lagged intervals, 2-order is lagged, estimated results are shown in the following Table, coefficient estimation values are in the above of the Table, $\mathrm{T}$ testing values are in the following, * expresses significance level.

Table 6. Estimation results of var model

\begin{tabular}{|c|c|c|c|c|}
\hline Sample interval(after & ent) final & 995 to fine & 2016 & \\
\hline Sample number: 85( & of the end & ter) & & \\
\hline Explained variables & loge & $\Delta m c-u$ & $\Delta y c-u$ & $\Delta I c-u$ \\
\hline$R^{\wedge} 2$ & 0.9966 & 0.99 & 0.97 & 0.95 \\
\hline Adjusted $R^{\wedge} 2$ & 0.9961 & 0.99 & 0.97 & 0.94 \\
\hline Fstatistics & 2119.06 & 10446.21 & 338.26 & 137.29 \\
\hline & $1.28^{* * *}$ & $0.16^{* * *}$ & -1.44 & $0.14^{* * *}$ \\
\hline loge $(-1)$ & -11.06 & 6.42 & -1.09 & 9.91 \\
\hline Joget & $-0.32^{* *}$ & -0.03 & -0.16 & 1.38 \\
\hline $\log (-2)$ & -2.75 & -1.71 & -0.12 & 1.93 \\
\hline A 1 (1) & $0.42^{* * *}$ & $0.56^{* *}$ & $2.07^{* *}$ & -2.3 \\
\hline 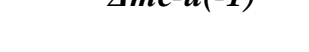 & 17.6 & 3.34 & 2.36 & -0.47 \\
\hline 4 & $0.04^{* * *}$ & 0.39 & 1.16 & -0.58 \\
\hline$\Delta m c-u(-2)$ & 4.7 & 0.17 & 1.71 & -0.12 \\
\hline (1) $0(1)$ & $-0.09^{* * * *}$ & $0.09^{* *}$ & $-2.27^{* *}$ & $1.55^{* * *}$ \\
\hline$\Delta y c-u(-1)$ & -12.35 & 2.13 & -2.66 & 4.82 \\
\hline (2) & $-0.05^{* * *}$ & $1.55^{* * *}$ & $2.44^{* *}$ & $0.08^{* * *}$ \\
\hline$\Delta y-x(-2)$ & -6.29 & 4.82 & 2.63 & 3.15 \\
\hline & $0.006^{* *}$ & -0.74 & 0.013 & $0.47^{* * *}$ \\
\hline$\Delta(x-2)$ & 2.78 & -1.19 & 1.13 & 6.06 \\
\hline $\left.1 / h_{0}\right)$ & $1.36^{* *}$ & $-0.04^{* * *}$ & 0.04 & 0.37 \\
\hline$\Delta 1 c-u(-2)$ & 3.51 & -4.45 & 0.94 & 0.04 \\
\hline 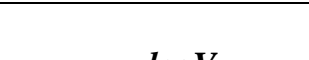 & $0.08^{* *}$ & $-0.64^{* * *}$ & $2.27^{* *}$ & $-0.64^{* * *}$ \\
\hline $\log \mathrm{v}$ & 2.16 & -3.91 & 2.65 & -3.91 \\
\hline Jag & $-0.06^{* * *}$ & 0.018 & -0.33 & 0.014 \\
\hline 1090 & -8.73 & 0.1157 & -0.47 & 0.09 \\
\hline JogEL & $0.09^{* *}$ & -1.61 & $2.38^{* *}$ & -1.61 \\
\hline logFIK & 2.16 & -0.36 & 2.7 & -0.36 \\
\hline
\end{tabular}

\subsection{Analysis of Model Empirical Results.}

Influential factors of RMB exchange rate.

According to the estimation results of Table 6, it can be seen that VAR system has systematically explained 99.66\% of RMB exchange rate fluctuation, F value of the model is 2119.06. The model is significant as a whole, $\mathrm{T}$ value of every coefficient also displays that coefficient is probably significant. Therefore, the explanation degree of model on RMB exchange rate influential factors is greater. And the symbol plus or minus of every estimated parameter is consistent with the settings of the previous theoretical elastic price currency model, and it is statistical significant (borrowing $\mathrm{T}$ test 
values of every coefficient). The acquisition of this result has proved the greater and significant explanation degree of currency model on RMB exchange rate. In the following, this paper will analyze the effects of every factor on RMB exchange rate one by one.

Effects of excessive currency. In this model, excessive currency is set as the numerical value balance by Sino-America. From the coefficient values of estimation, excessive currency has the maximal effects on RMB exchange rate, because it has greater explanation degree on RMB exchange rate and its previous coefficient value is greater. Therefore, currency excessive issuing will lead to the worsening RMB depreciation, and its function is significant.

Effects of economic increase and interest rate level. With the above analysis, this paper puts forward that excessive currency is the main factor to influence RMB exchange rate. For the effects of additional two endogenous on RMB exchange rate in the model, this paper also makes the assessment. Assessment values indicate that although the estimated value of Sino-America economic increase rate differentiated coefficient is significant, its effects of economic increase (including its first-order lagging term) on RMB exchange rate are greater (reverse promotion).

Effects of exogenous variables in the model. There are three exogenous variables in the model: currency circulation velocity (M2/GDP), capital account openness degree (A-open) as well as the effects of financial relevance rate on RMB exchange rate. After the assessment, it is found to be significant, among which currency circulation velocity with financial relevance rate and RMB exchange rate, the increasing values will lead to the depreciation of RMB exchange rate. The smaller the administrative regulation degree of the capital account, the higher the openness degree, the more obvious depreciation trend of RMB will be.

\section{Political Advice}

Under the framework of elastic price currency model, it analyzes the influential factors of RMB exchange rate fluctuation and"The secret of China", which makes us clarify the reasons of the pressures from the appreciation of RMB currently. In addition, we can have certain understanding of the future trend of RMB exchange rate, which is beneficial to enlightening new thinking on the domestic RMB exchange rate system reform issue. This paper has concluded four points of enlightenment as below: 1. improving the domestic property right system;2. stabilizing salary fluctuation rate; 3 . transiting economic increase mode, improving the domestic economic efficiency; 4. gradually loosing the administrative regulation on capital account.

\section{References}

[1] Liu Wei, Li Shaorong, Li Sunyu. Monetary Expansion, Economic Growth and Institutional Innovation of Capital Market [J]. Economic Research Journal, 2002(1): 27-32+94.

[2] Ai Hongde, Fan Nan. An Empirical Analys is of Monetary Velocity in China [J]. The Journal of World Economy, 2002(8): 53-59+80.

[3] He Yan. RMB Exchange Rate, Firms Innovation and Survival [J]. International Economics and Trade Research, 2017, 33(6): 51-68.

[4] Zhang Ailian, Tang Shi, Liu Ba. The Formation Mechanism and Internationalization Process of Bilateral Fluctuation of RMB Exchange Rate [J]. Journal of Shanxi University (Philosophy and Social Science Edition), 2017, 40(6): 46-52. 